\title{
SEGMENT ROUTING AS A BASIS FOR SOFTWARE DEFINED NETWORK
}

Nikita S. Kalmykov, MTUCI, Moscow, Russia, nikitakalmi25@gmail.com

Vladimir A. Dokuchaev, MTUCI, Moscow, Russia, v.a.dokuchaev@mtuci.ru
Manuscript received 27 April 202I;

Accepted 28 May 2021

Keywords: segment routing, software-defined networks, path computation element, MPLS, SR, SDN, path computation element protocol, PCE, PCEP

In this article the structure, main components and functioning of Segment Routing (SR) are analyzed. Segment routing is a WAN traffic routing technique existing on MPLS and only-BGP networks. Segment routing is also considered as a way of improving the infrastructure performance and efficiency. The main advantages of SR are achieved through the implementation of the SDN concept approach, without changing the standard data transferring plane for each of the technologies, above which SR can be applied. The article also covers the main areas of SR technology application, interaction in a centralized and decentralized network. The article provides the examples of controllers for SDN implementation using SR. The presence of a controller in the network permits the realization of bandwidth on demand, traffic prioritize, selection of the most suitable route in the network for different types of traffic easier and more often without any protocols or devices. Another important advantage of controller's implementation on networks using SR can be a reduction of the services recovery time after a failure, because the route will be rebuilt faster (compared to MPLS). SR can be considered as an opportunity to refuse from such protocols as LDP or RSVP for situation when used on a network in tandem with a controller. IPv6 networks, using SR, are able to acquire additional capabilities in programmability and flexibility.

Information about authors:

Nikita S. Kalmykov, BSc (Eng), Student of Master's degree, MTUCl, Moscow, Russia

Vladimir A. Dokuchaev, DSc (Tech), Professor, Head of the Department "Network Information Technologies and Services" MTUCI, Moscow, Russia

\footnotetext{
Для цитирования:

Калмыков Н.С., Докучаев В.А. Сегментная маршрутизация как основа программно-конфигурируемой сети // Т-Сотm: Телекоммуникации и транспорт. 202I. Том I5. №7. С. 50-54.

For citation:

Kalmykov N.S., Dokuchaev V.A. (202I) Segment routing as a basis for software defined network. T-Comm, vol. I5, no.7, pp. 50-54.

(in Russian)
} 


\section{Introduction}

Wide Area Networks (WAN) are an essential link for the majority of people and companies around the world. The Internet has become the most important unifying element in the work of almost all infrastructure, in many ways, the basis of modern business. Modern wide area networks began their existence in the late 60s of the 20th century. Their prototype was the ARPANET network, developed for military research purposes in the United States.

The history of WAN networks can be represented in three stages.

- Since the mid-1980s, converged networks have become more and more popular, with a multitude of applications being developed to transfer various types of data.

- $\mathrm{n}$ the late 1980s and 1990s, in converged transport networks dominated such protocols as Frame-Relay (FR) and Asynchronous Transfer Mode (ATM).

- I the early 2000s, the Multiprotocol Label Switching (MPLS) mechanism was developed, which was designed to help solve the problem of "joints" in the global network with the networks of telecom operators, as well as manage communications using labels, not relying solely on IP addresses more efficiently and quickly. It is important to note that this approach combines the speed advantage of L2 with the flexibility of L3.

\section{Segment routing and SDN}

In the second half of the 2010s, MPLS technology became widespread. The active using of this technology has allowed telecom operators and large corporate clients to transfer large amounts of data quite efficiently and with high bandwidth. This technology allows setting a specific label stack on the border router, and all marked packets using this stack will be transmitted over the network without additional analysis of the IP header at intermediate nodes. The usage of MPLS allows telecom operators to implement almost any service (set of services), transfer data of any protocols (for example, Ethernet, PPP, HDLC), build overlay networks from L2 / L3 VPN, implement various interactions between networks operator (for example, Carrier Supporting Carrier) [1]. Schematic representation of an MPLS / VPN domain (operator's network) has been shown in Figure. 1, where:

- $\quad \mathrm{PE}$ - provider edge router;

- $\quad \mathrm{CE}$ - customer edge router that is connected directly to the provider edge.

Operator's network routers form an MPLS domain.

From the point of view of the edge router (PE), the work with labels comes down to performing several actions, such as: push (encapsulate a specific set of labels), pop (de-encapsulate a label stack) and swap (replace one label with another one). For telecommunications equipment vendors it was not a big task to implement MPLS support for many of their products. The implementation of MPLS meant making changes only in the software part of the products. A significant disadvantage of the technology was the complexity of configuration and the need for a large number of accompanying protocols for the distribution of routing information (Link-State protocols OSPF / IS-IS), labels exchange (LDP / RSVP) as well as the organization of the control plane (MP-BGP / Target-LDP). Thus, in the situation with the MPLS usage, a dilemma arose, consisting in the simple organization of the work of the data plane, and the rather laborious organization of the control plane work.

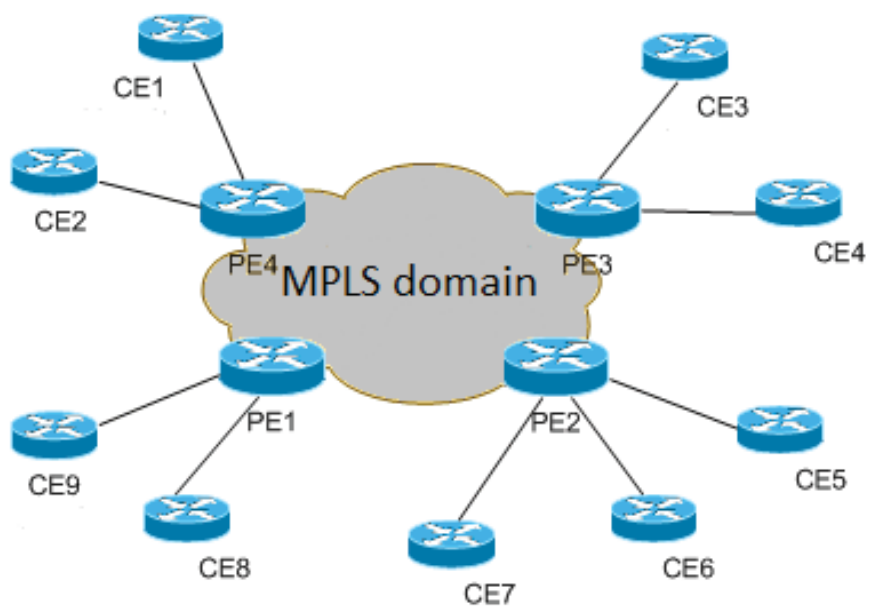

Fig. 1. Scheme of MPLS domain and client nodes

The Segment Routing technology can become a solution for the current problem of the control plane operation simplifying, while maintaining the efficiency and simplicity of the data transfer plane [2]. In 2013, Cisco Systems proposed to develop an updated architecture for building data transmission networks, which was named Segment Routing (SR). SR technology is based on the principles of source routing - the ability to specify the path of packets at the source using a sequence of segments in the packet's header. A segment is usually understood as a description or instruction for the passage of packets from one point to another. For example, such an instruction may be a requirement to deliver a packet (a set of packets) from point A to point $\mathrm{B}$ along the shortest path, or using a specific path. Thus, routers on the path of the packet can be guided by the rule originally written in the packet header. As a measure of backward compatibility with MPLS, the possibility of using MPLS-tags was considered (when transmitting traffic in MPLS networks) or additional IPv6 Routing Headers in the case of working in only-IPv6 networks. Due to maintaining a simple and already proven data transfer layer for routers, there is no need to revise their standard operating logic. Routers continue to work with push, pop and swap rules, as they did in the MPLS network.

It is necessary to touch upon the implementation of the control plane separately. When forming the path of the packet, instructions for the nodal equipment are written in the header segments. To describe the path of a packet through the network of an operator (or several operators), information about: identifiers of nodes (routers) on the path, and identifiers of the interfaces of these nodes is necessary. Typically, this information is specific to IGP routing protocols. For example, the implementation of the OSPF and IS-IS protocols assumes the storage of information about all network elements and all connections between these elements.

The node identifier in SR terminology is called Prefix / Node SID. This parameter is set when configuring the router, and from the point of view of traffic delivery instructions, its use will mean "to deliver the packet along the shortest path to the required node”. A dedicated range is used to assign SR labels to avoid overlaps with "classical" protocols. This range is called SRGB - Segment Routing Global Block. 
The default values for the IOS XR platform are 16000-23999. The shortest path is often determined by the IGP routing protocols. To determine the label of a specific device, the SID assigned to the device will be added to the lower SRGB boundary. For the data plane of the intermediate router, receiving the Prefix / Node SID is the same as swap. For determining the target router interface (PE), the SR provides the Adjacency SID value. Adjacency SID is automatically generated for each SR neighbor, and allows traffic to be transmitted over a specific interface. An important note is that this value is unique only within a single router. When traffic is transmitted, the labels are transmitted over the network by the IGP routing protocols, and, in this case, the Prefix / Node SID and Adjacency SID label stack will be unique, which allows to specify the device itself and the interface - such a scheme is shown in Figure 2.

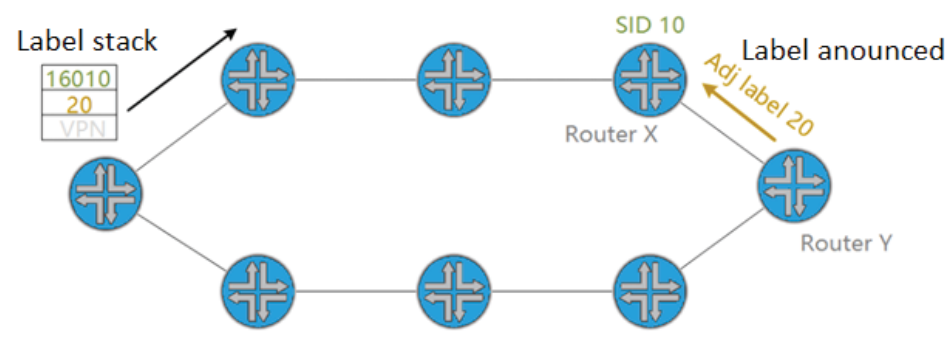

Fig. 2. SR using Prefix / Node SID and Adjacency SID label stack

Thus, there is no need for an additional protocol for distributing labels over the network, such as LDP (Label Distribution Protocol) or RSVP (Resource ReSerVation Protocol) when using SR. SR allows simplifying interaction with the control plane, reducing the incorrect network configuration possibility, in comparison with LDP and RSVP, and also permits to refuse from using of additional protocols. Another important advantage of SR is the ability to balance traffic when metrics in different paths coincide automatically, taking into account the growing demand for data transmitted over the network. However, there is a need to reserve bandwidth, and in this case the input of a PCE (Path Computation Element) is required.

Installing such a controller allows to configure the calculation of tunnels with various attributes, including the bandwidth attribute. The PCE controller communicates with network elements using PCEP (Path Computation Element Communication Protocol). It should be noted that PCE can be used in the network in conjunction with the RSVP, LDP protocols, and even statistically assign labels. For any use case, the general task of the PCE is to work with the transfer rules for devices using the PCEP protocol [3], a schematic representation is shown in Figure 3.

To calculate the path, the PCE controller needs information about the network topology, often such information will be provided with the controller by connecting it to the IGP domain (including in the current network topology).

The most important advantages of PCE are:

- $\quad$ Ability to monitor the load on interfaces, and reroute if necessary (in case of failure);

- $\quad$ Ability to monitor network status;

- Implementation of functional that increases the flexibility and easier of network configuration.

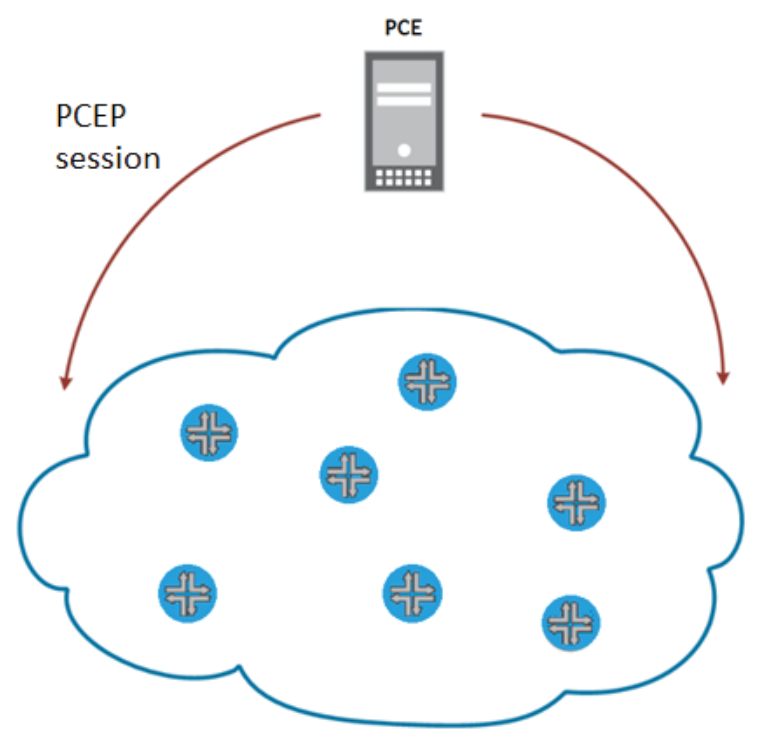

Fig. 3. Network scheme with PCE controller

Thus, the PCE can be called a software defined network (SDN) controller over the existing MPLS network. Some open source SDN projects support the PCEP protocol, such as the Open Daylight controller [4].

Implementation of SDN principles for a transport network with SR permits to achieve such important aspects of network management flexibility increasing, of new services deployment simplicity and subsequent configuration. It's important to note, the implementation of the PCE controller in the network does not require a network redesign and can work above the already existing data transfer plane.

If it is necessary to describe transport MPLS networks using SR in terms of SDN networks, then the scheme of interaction between planes (data transmission, control) they will look like this, Figure 4.

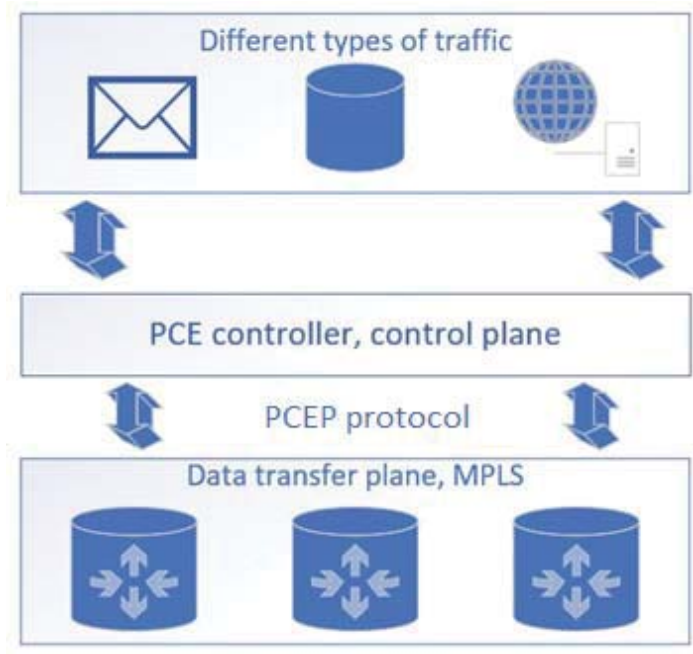

Fig. 4. MPLS transport network architecture using PCE controller

The PCE controller using on the transport network allows to manage the traffic path in such a way that the aspects most critical for a particular type of traffic will be taken into account [5]. 
For example: for traffic that requires as much bandwidth as possible, the most suitable route will be selected out of several possible ones.

\section{SR use cases}

As an example of SR technology usage, consider a certain operator's network, which consists of 300 routers. Each router is connected to neighboring routers through 5 interfaces. In that case if all traffic paths in the network (full mesh) are considered, when using SR in this network, the switching table on each router will contain a total of 305 entries. These entries contain 300 Prefix / Node SIDs and 5 Adjacency SIDs. On each router, such a table will be unchanged and finite, due to the fact that it does not depend on the number of traffic transmission paths and reflects only the number of routers in a given network and the number of connections between them. Different traffic flows in the network will have different segment values and differ in the size of the stack, however, the switching table will not change, and depend on the number of flows. In the case of solving a similar problem using OpenFlow (or other protocols), each traffic flow will need to be programmed on each of the routers [6]. This is an almost non-scalable solution. A similar situation will occur when using RSVP TE, and the most common MPLS approach with Full Mesh RSVP TE. For each TE tunnel, there will be a separate entry in the switching table (TE midpoint) on intermediate routers, which may affect the final scalability. Another important aspect will be the fault tolerance of such a solution: if any link breaks between routers, a very active exchange of signaling messages will take place (with active rebuilding of RSVP tunnels), and the resources of the control plane will be actively involved in this process, calculating the most optimal routes.

As a second, no less relevant example, the use of the SR architecture in software defined networks should be cited. Consider the following situation: it is necessary to provide a certain bandwidth for an application (for example, 2 Gbps) through the operator's network. The role of the link between the application and the operator's network is played by the SDN controller, which analyzes the application's requirements and at the same time has information about the network topology and channel load [7]. Such a controller can be represented by:

- Controller based on one of the Open Source solutions (for example, Open Daylight);

- Vendor's proprietary solution.

The WAN Automation Engine controller from Cisco Systems [8] is an example of such a proprietary solution. This controller can provide the required application programming interfaces (APIs) for different applications and client services. WAN Automation Engine allows load balancing between different channels using the afore mentioned PCEP protocol. Of course, RSVP allows to implement identical functionality, but balancing can only be implemented between tunnels created in manual mode, while SR allows to automate this process significantly.

After analyzing the required bandwidth by the application and based on information about the current state of the network (for example, when the channel is congested between certain routers), the controller can calculate a suitable path for traffic in the network and signal a specific label stack to the router. The label stack will be applied to the traffic flow from the application. For different types of applications, the set of network re- quirements may differ, which means that the traffic routes may be different, in this case the controller will be able to form the required set of segments each time maximally flexibly. Such a bundle of controller and SR technology allows not to change the topology and does not require reprogramming each router to pass traffic from applications with the required priority. Due to a centralized operation of the network management level, the situation of signaling messages "storm" of in the network is practically excluded, and the number of signaling messages itself is significantly reduced.

\section{Conclusion}

In conclusion, it must be said that data transmission networks have been constantly evolving throughout their existence. Segment Routing technology is possibly the next evolutionary step after MPLS. The fact that such technologies are in demand is evident from the interest of telecom operators, backbone providers, large corporate clients, etc. The indisputable advantage of SR is the ability to work within the SDN concept without active renewal of the equipment fleet (except for equipment without MPLS support, in some cases and equipment older than 4-5 years), thus reducing implementation requirements. An equally important advantage is the ability to use fewer associated protocols and technologies. A significant reduction of the complexity of setting the control plane, a reduction of the volume of transmitted service information make the technology attractive to the end client [9]. The most significant application areas of the technology:

- Operator networks functioning simplification. The possibility of refusal from several additional protocols plays the most significant role in this case.

- $\quad$ Fast route change. SR can be used in networks of service providers that offer critical-mission services that require rapid recovery of data transmission.

- $\quad$ Traffic control in the SR network has become one of the widespread use cases for segment routing due to its simplicity and scalability. Currently, traffic control in MPLS is rarely used on large provider networks due to the high complexity.

- $\quad$ SR can be used in a centralized, distributed, or hybrid environment. In a distributed scenario, segments are allocated and signaled via IS-IS, OSPF, or BGP. In a centralized scenario, segments are allocated and instantly created by the SR controller (SDN controller).

- Improving network programmability when it is used in IPv6 networks. Due to the concept of instruction sets, SR expands the programmability of the network.

- $\quad$ Possible usage for the 5G networks, up to the replacement of SR in the IPv6 version (SRV6) of the User Plane Tunneling Protocol (GTP-U), which has been used in mobile networks since the implementation of LTE.

Thus, a rather wide range of possibilities for using SR in various networks, scalability flexibility and simplicity make it very perspective for usage.

\section{References}

1. Goldstein, A. and Goldstein, B., 2005. MPLS Technology \& Protocols. St. Petersburg: BHV.

2. Segment Routing. n.d. Segment Routing. [online] Available at: $<$ https://www.segment-routing.net/> [Accessed 7 February 2021]. 
3. Tools.ietf.org. n.d. RFC 5440 - Path Computation Element (PCE) Communication Protocol (PCEP). [online] Available at: $<$ https://tools.ietf.org/html/rfc5440> [Accessed 11 February 2021].

4. OpenDaylight. n.d. Current Release: Aluminum OpenDaylight. [online] Available at: <https://www.opendaylight.org/current-release-aluminium> [Accessed 15 February 2021].

5. Support.huawei.com. n.d. Segment Routing - Huawei EDOC1100092117. [online] Available at: <https://support.huawei.com/enterprise/en/doc/EDOC1100092117> [Accessed 20 February 2021].

6. Kalmykov, N. and Dokuchaev, V., 2020. SOFTWAREDEFINED NETWORKS CONCEPT APPLICATION FOR GEO-
GRAPHICALLY DISTRIBUTED NETWORKS DEVELOPMENT. Telecommunications and information technology, 7(2), pp.51-56.

7. Kalmykov, N. and Dokuchaev, V., 2020. ANALYSIS OF PROTOCOLS IMPLEMENTING SDN TECHNOLOGY. Telecommunications and information technology, 7(1), pp.19-25.

8. Cisco WAN Automation Engine (WAE). [online] Cisco. Available $\quad<$ https://www.cisco.com/c/en/us/products/routers/wanautomation-engine/index.html> [Accessed 21 February 2021].

9. Ray Mota 2018. Segment Routing with Use Cases. [online] Available

$<$ https://www.researchgate.net/publication/327515548_Segment_Routin g_with_Use_Cases> [Accessed 26 February 2021].

\title{
СЕГМЕНТНАЯ МАРШРУТИЗАЦИЯ КАК ОСНОВА ПРОГРАММНО-КОНФИГУРИРУЕМОЙ СЕТИ
}

\author{
Калмыков Никита Сергеевич, Бакалавр, МТУСИ, Москва, Россия, nikitakalmi25@gmail.com \\ Докучаев Владимир Анатольевич, МТУСИ, Москва, Россия, v.a.dokuchaev@mtuci.ru
}

\section{Аннотация}

В статье анализируются структура, основные компоненты и функционирование Segment Routing (SR). Сегментная маршрутизация - это метод маршрутизации трафика WAN, существующий в сетях MPLS и only-BGP. Сегментная маршрутизация также рассматривается как способ повышения производительности и эффективности инфраструктуры. Основные преимущества SR достигаются за счет реализации концептуального подхода SDN без изменения стандартной плоскости передачи данных для каждой из технологий, выше которых может применяться SR. Также в статье освещены основные направления применения технологии SR, взаимодействия в централизованной и децентрализованной сети. Приведены примеры контроллеров для реализации SDN с использованием SR. Наличие контроллера в сети позволяет реализовать полосу пропускания по запросу, расставить приоритеты трафика, выбрать наиболее подходящий маршрут в сети для различных типов трафика проще и чаще без какихлибо протоколов или устройств. Еще одним важным преимуществом реализации контроллеров в сетях, использующих SR, может быть сокращение времени восстановления сервисов после сбоя, поскольку маршрут будет перестраиваться быстрее (по сравнению c MPLS). SR можно рассматривать как возможность отказаться от таких протоколов, как LDP или RSVP, для ситуации, когда они используются в сети в тандеме с контроллером. Сети IPv6, использующие SR, могут получить дополнительные возможности программирования и гибкости.
\end{abstract}

Ключевые слова: сегментная маршрутизация, программно-конфигурируемые сети, элемент вычисления пути, MPLS, SR, SDN, npoтокол элемента вычисления пути, РCE, РCEP.

\section{Литература}

І. Гольдитейн А., Гольдитейн Б. Технология и протоколы MPLS. Санкт-Петербург: BHV, 2005.

2. Segment Routing. n.d. Segment Routing. [online] Available at: <https://www.segment-routing.net/> [Доступ 7 февраля 202I].

3. Tools.ietf.org. n.d. RFC 5440 - Path Computation Element (PCE) Communication Protocol (PCEP). [online] Available at: <https://tools.ietf.org/html/rfc5440> [Доступ II февраля 202I].

4. OpenDaylight. n.d. Current Release: Aluminum - OpenDaylight. [online] Available at: <https://www.opendaylight.org/current-release-aluminium> [Доступ I5 февраля 202I].

5. Support.huawei.com. n.d. Segment Routing - Huawei EDOCII00092II7. [online] Available at: <https://support.huawei.com/enterprise/en/doc/ EDOCII00092II7> [Доступ 20 февраля 202I].

6. Калмыков Н., Докучаев В. Применение концепции программно-определенных сетей для разработки географически распределенных сетей // Телекоммуникации и информационные технологии, 2020. №7 (2). С. 5I-56.

7. Калмыков Н., Докучаев В. Анализ протоколов, реализующих технологию SDN // Телекоммуникации и информационные технологии, 2020. №7 (I). C.19-25.

8. Cisco WAN Automation Engine (WAE). [online] Cisco. Available at: <https://www.cisco.com/c/en/us/products/routers/wan-automationengine/index.html> [Доступ 2I февраля 202I].

9. Ray Mota 2018. Segment Routing with Use Cases. [online] Available at: <https://www.researchgate.net/publication/ 3275 I5548_Segment_Routing_with_Use_Cases> [Доступ 26 февраля 202I].

Информация об авторах:

Калмыков Никита Сергеевич, бакалавр, студент магистратуры, МТУСИ, Москва, Россия

Докучаев Владимир Анатольевич, д.т.н., профессор, заведующий кафедрой "Сетевые информационные технологии и сервисы", МТУСИ, Москва, Россия 